Natural Hazards and Earth System Sciences (2001) 1: 165-170

(C) European Geophysical Society 2001

\title{
Recent results of the research for preseismic phenomena on the underground water and temperature in Pieria, northern Greece
}

\author{
M. E. Contadakis and G. Asteriadis \\ Department of Geodesy and Surveying, University of Thessaloniki, GR-54006, Thessaloniki, Greece
}

Received: 12 June 2000 - Accepted: 6 January 2002

\begin{abstract}
The recent results of the research for earthquake precursory phenomena on the underground water level and temperature at the area Pieria of northern Greece are presented. The analysis of our observations in relation to the local microseismicity indicate that underground water level variations may be considered as precursory phenomena connected to the local microseismic activity in the area of Pieria. Base on these results, it can be supported that monitoring the shallow underground water level and temperature for detecting earthquake precursory phenomena may be proved to be a useful method in the framework of an interdisciplinary research for earthquake prediction.
\end{abstract}

\section{Introduction}

Crustal movements, expansion or contraction of the ground, associated with a tectonic activity, which may result in an earthquake, cause changes in the pore pressure of the underground rocks and deformation of the underground water system, which can be observed as changes in the underground water level and temperature.

For this reason the sudden or unusual changes in the level or in the temperature of the underground water could be considered as precursory phenomena of a forthcoming earthquake. Yamaguchi (1980), Rikitake (1981), Oki and Hiraga (1988), Asteriadis and Livieratos (1989) and Asteriadis and Contadakis (1993) reported changes in the level and temperature of the underground water in relation to premonitory effects of an earthquake. Wakita (1982) believes that the changes in the underground water level and temperature are important earthquake-related phenomena, and that for the purpose of earthquake prediction it is essential to know the changes (increase or decrease) in the level and temperature of the underground water that take place near the Earth's surface at the time of earthquakes.

Correspondence to: M. E. Contadakis

(kodadakis@vergina.eng.auth.gr)
Due to great interest and the problem Greece has with short-term earthquake prediction, the Department of Geodesy and Surveying of the University of Thessaloniki is engaged in the study of the underground water level and temperature in areas with high seismic risk over the last fifteen years (Contadakis and Asteriadis, 2001). In this paper, we present the recent results of the underground water and temperature follow-up in relation to the seismicity for the area of Pieria in Macedonia, Greece.

\section{The area and the network}

The area of Pieria is lying northeast of Mount Olympus in north Greece. This area (Fig. 1) is extended between the $40^{\circ} .16 \mathrm{~N}$ and $40^{\circ} .30 \mathrm{~N}$ parallels and by the $22^{\circ} .33 \mathrm{E}$ and $22^{\circ} .50 \mathrm{E}$ meridians and is bounded by Mt. Olympus (with $2917 \mathrm{~m}$ height) to the south, Pieria Mountain to the west and the Thermaikos Gulf (North Aegean Sea) to the east.

The rocks north of the Mt. Olympus area is limestone and dolomite limestone, while the south is carbonate sediments. The tectonic activity is connected with the activity of a number of normal faults with NNW-SSE direction and also with a few normal faults with NE-SW direction (Fig. 1). This area, in general, belongs to the Olympus-Ossa unit which belongs to the "lower plate" which acted as the foreland during the Tertiary collision of the southern branch in the Alpine orogen (Kilias et al., 1991). Although Dion, a famous ancient city and now a small village in the area, was ruined twice by destructive earthquakes during the fifth century, the area appears to be seismically quiet during the last century (Papazachos and Papazachou, 1997). Nevertheless, a microseismic activity started in the area during the year 1999. In this area is the town of Katerini with more than 45000 people and just before the ascent to Olympus, $17 \mathrm{~km}$ south of Katerini, is Dion. In the regions of these towns we installed two stations, $\mathrm{S} 1$ and $\mathrm{S} 2$. 

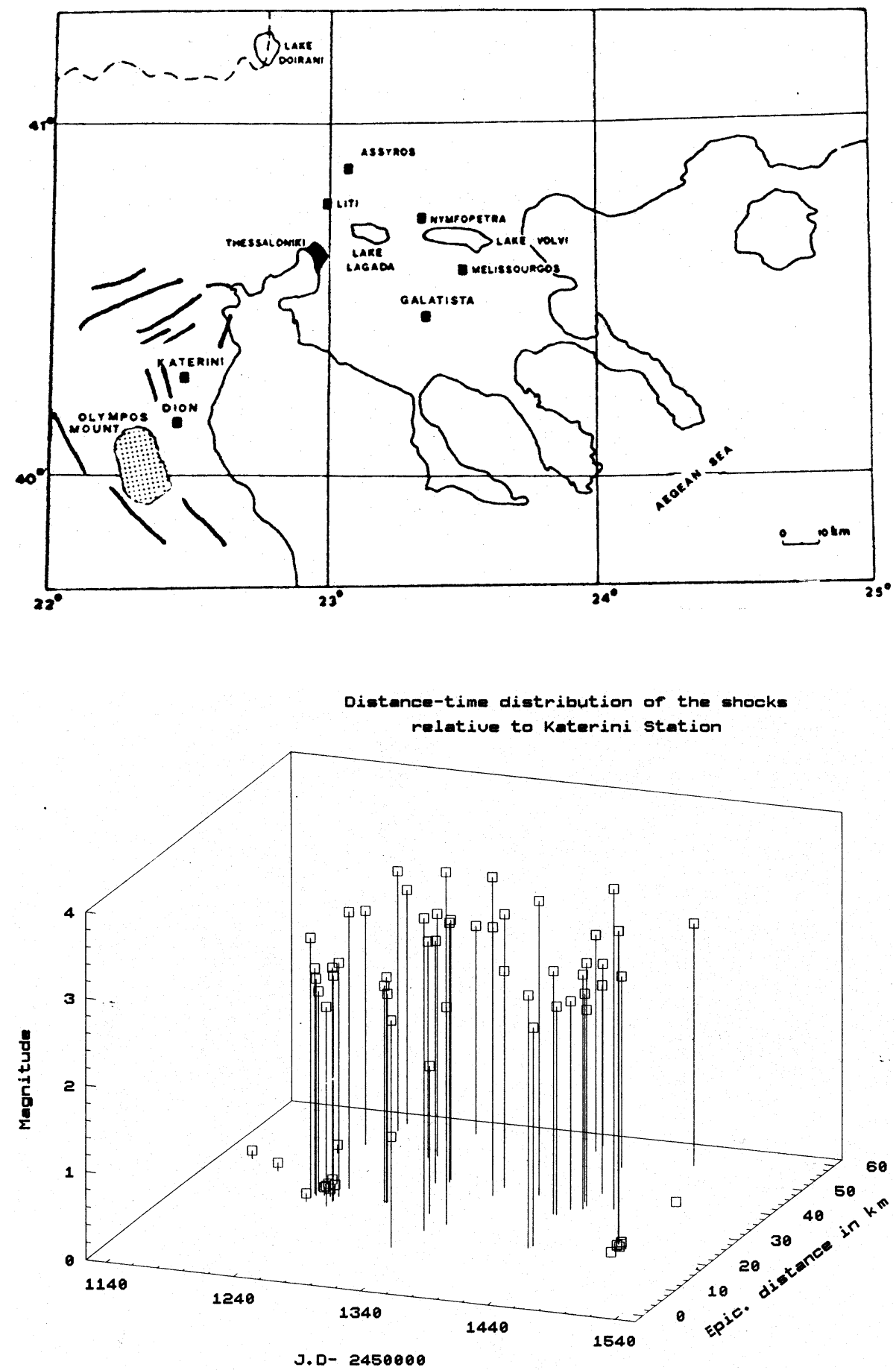

Fig. 1. The area of Pieria in which the system of the faults are also traced.
Fig. 2. Magnitude and epicentral distance of the shocks from Katerini.

\section{The network and the observational material}

\subsection{Hydrological and meteorological data}

The station $\mathrm{S} 1$ is a borehole of $85 \mathrm{~m}$, which faces a confined aquifer in Katerini. In this station we installed a "Geokon" Model 4500-AL vibrating wire piezometer with single channel data logger for recording the ground water elevation and temperature automatically and continuously with an accuracy of $1 \mathrm{~mm}$ in level and $0^{\circ} .1$ centigrade in temperature. The
Table 1. Position and depth of the wells at the network-stations and the sampling frequency of the performed measurements

\begin{tabular}{cccccc}
\hline Well & $\begin{array}{c}\text { Long } \\
{\left[{ }^{\circ}\right] \mathrm{N}}\end{array}$ & $\begin{array}{c}\text { Lat. } \\
{\left[^{\circ}\right] \mathrm{E}}\end{array}$ & $\begin{array}{c}\text { Height * Depth } \\
\mathrm{t}(\mathrm{m})\end{array}$ & $\begin{array}{c}\text { Lag of } \\
(\mathrm{m}) .\end{array}$ & Meas. \\
\hline S1 & 40.27 & 22.49 & 30.66 & 16.00 & Hourly \\
S2 & 40.16 & 22.47 & 70.56 & 62.6 & Daily \\
\hline
\end{tabular}



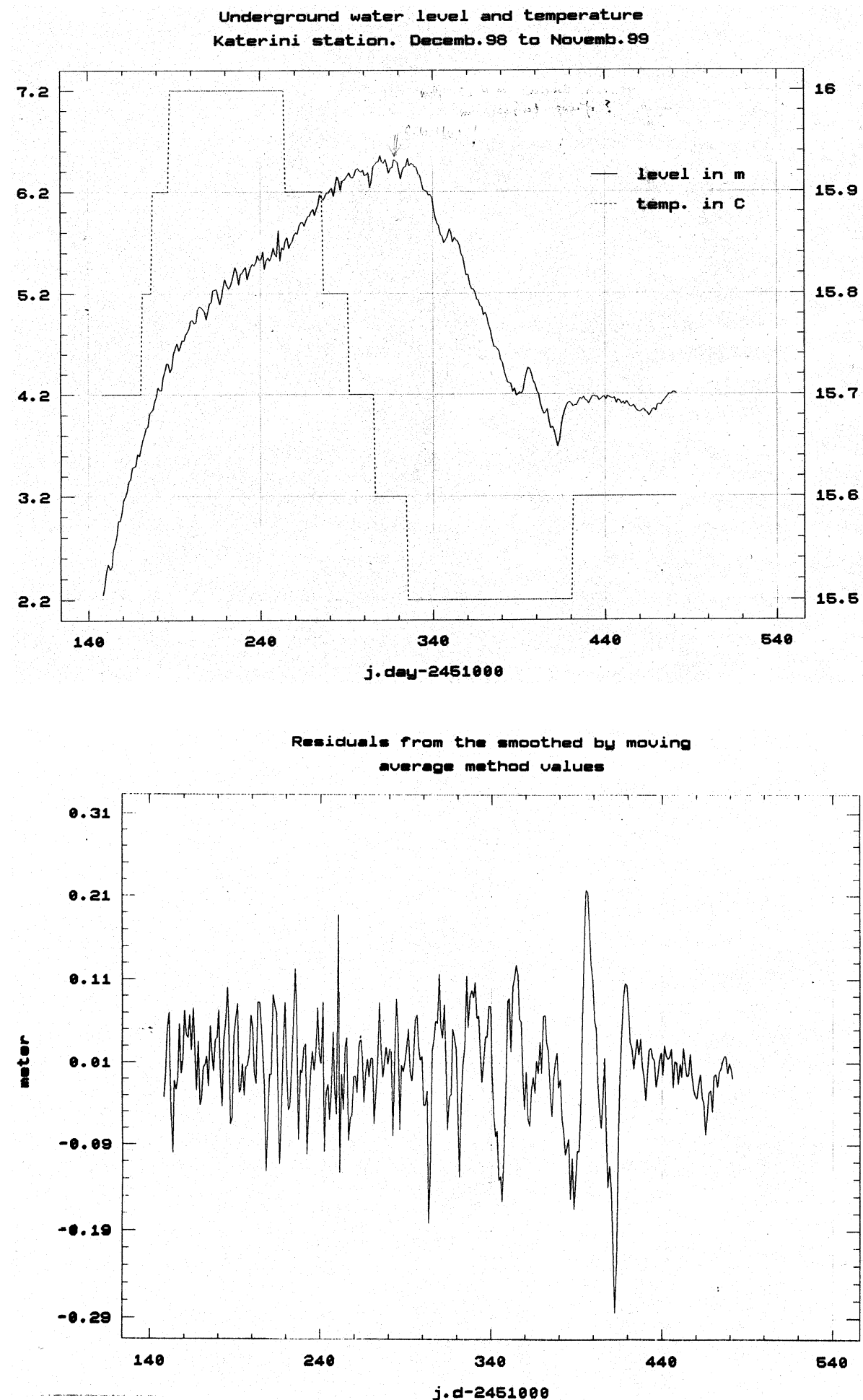

Fig. 3. Variations of the underground water temperature and level in Katerini well.
Fig. 4. Deseasonated water level variations (D.L). sampling interval at this station is one hour.

The station S2 is a borehole of $149 \mathrm{~m}$, which faces an unconfined aquifer in Dion. In this station we installed a "Solinst" Model 101 water level meter. The sampling interval at this station is one day. Table 1 gives the positions and depths of the wells at the network-stations and the sampling frequency of the performed measurements. In station 1 we also installed a "Weather Monitor II" mobile meteorological station of the American firm "Davis Instruments Corp.", for the continuous and automatic recording of the weather parameters, such as temperature, humidity, barometric pressure as well as daily and accumulated rainfall, in the area, in order to study the influence of the nontectonic factors, such as the precipitation, the barometric pressure as well as the Earth's tides in the underground water level measurements. The water level follow-up started on 24 January 1998 at Katerini and 


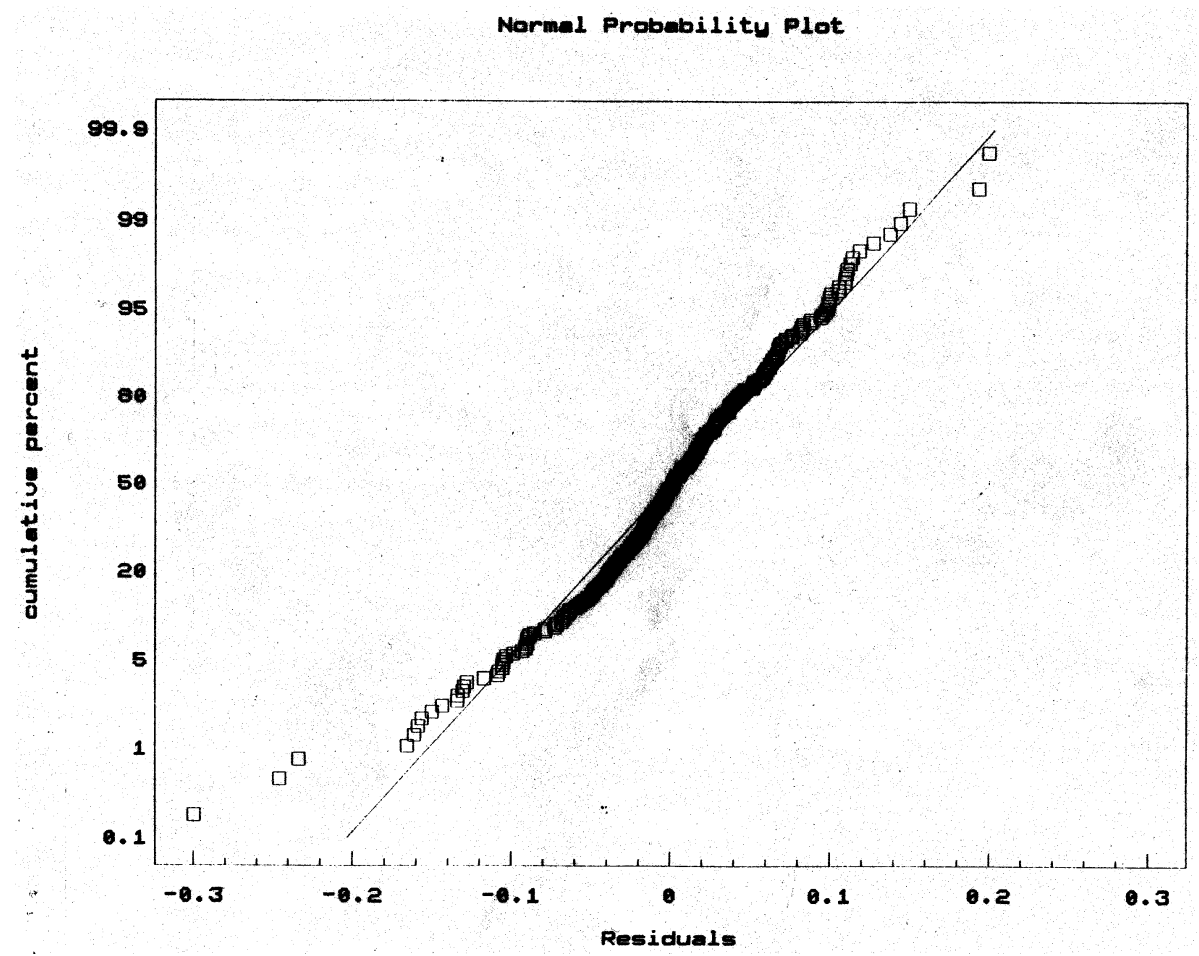

Fig. 5. Comulative percentage frequencies of the deseasonated, depressured and detided residuals (points), normal distribution (solide line). on 12 February 1998 at Dion and are continued until today in Katerini and until 15 March 1999 in Dion.

In this paper, we discuss the observational data which were sampled within the time period from 1 December 1998 to 30 November 1999.

\subsection{Seismic and tidal data}

We compare the hydrologic changes with the seismicity of an area of a geographical square degree centered to Katerini and extended from $22^{\circ} .0$ to $23^{\circ} .0 \mathrm{E}$ and $39^{\circ} .7$ to $40^{\circ} .7 \mathrm{~N}$, in order to compensate for the element of locality of the risky area. The seismic data for the test area were taken from the archives of the Seismological Station of the Department of Geology of the University of Thessaloniki. Within the above mentioned time interval, 68 shocks with magnitudes up to 3.8 occurred in the above mentioned area. All of them were shallow earthquakes with depths ranging from 0 to $15 \mathrm{~km}$.

Figure 2 displays the occurrence at the Julian date of the shocks, together with their magnitudes and epicentral distances from Katerini. It is seen that all of the epicentral distances of the shocks range from 12 to $55 \mathrm{~km}$, with the great majority of them occurring in an epicentral distance of 20 to $40 \mathrm{~km}$. Most of them constitute a seismic series.

The tidal gravity variations during the time interval of our observations at the sites of our stations were computed using the tidal parameters defined by Arabelos (2001).

\section{Results and discussion}

As it was reported in an earlier paper (Contadakis and Asteriadis, 2000) the barometric pressure and the Earth-tides have a significant synchronous influence on the underground water level of both wells, which have quite a similar behavior.

Figure 3 displays the variations of the underground water temperature and level in the Katerini well. It is seen that both quantities vary in a normal way for a confined aquifer, which has very little or no hydraulic connection to the surrounding soil, i.e. the temperature varies $0.5^{\circ} \mathrm{C}$ throughout the year, with a phase lag of 6 months with the atmospheric temperature. It is expected to vary the temperature of the ground in a similar depth and the water level presents a delayed seasonal precipitation respiration variation. Superimposed on the seasonal water level variation are smaller variations which can be attributed to the Earth's tide, barometric pressure, as well as to possible tectonic stresses. To detect any connection between water level variation and the seismicity in the test area we have to compare the deseasonated, depressured and detided residual variations of the water level with the seismicity.

Figure 4 displays the deseasonated water level variation (D.L) by subtracting the 21 sample moving average seasonal variation. From these residuals we deduce a multiregressional model for the level variations (LEV) with independent variables: the barometric pressure (B.P) and the tidal gravity variations (T.V):

$(\mathrm{LEV})=\mathrm{a}+\mathrm{b}(\mathrm{B} . \mathrm{P})+\mathrm{c}(\mathrm{T} . \mathrm{V})$,

where:

$\mathrm{a}=1.403 \pm 0.747 \mathrm{~cm}$ 

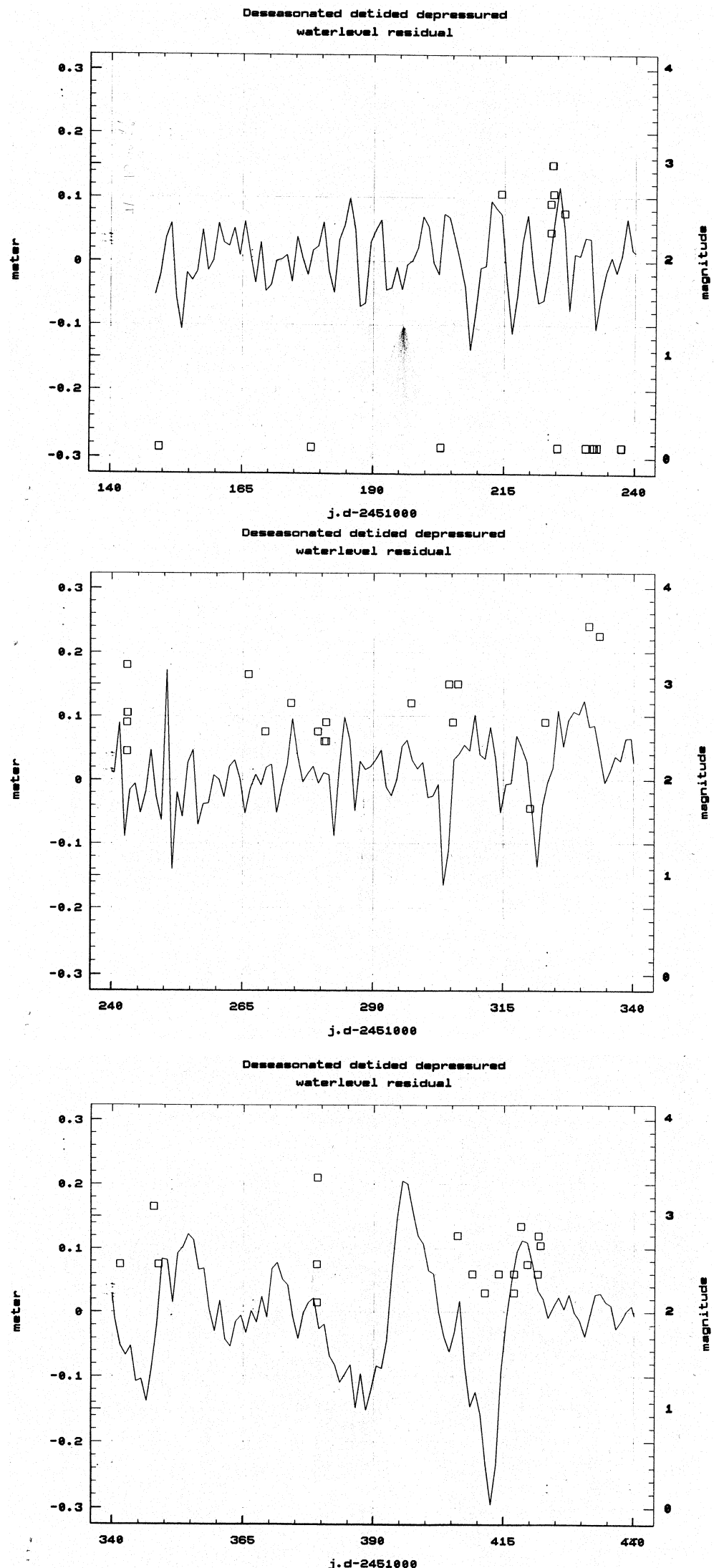

Fig. 6. (a) Deseasonated, depressured and detided residuals (D.R) and the shocks. (b) Deseasonated, depressured and detided residuals (D.R) and the shocks. (c) Deseasonated, depressured and detided residuals (D.R) and the shocks. 
$\mathrm{b}=0.00186 \pm 0.00099 \mathrm{~cm} / \mathrm{mbar}$

$\mathrm{c}=2.2 \times 10^{-5} \pm 6.56 \times 10^{-6} \mathrm{~cm} / \mu \mathrm{Gal}$.

The deseasonated, depressured and detided (D.R) variations are the residuals of the modeled variations (LEV) from the deseasonated variations (D.L). The standard deviation of the deseasonated, depressured and detided residuals is:

$\sigma_{(\mathrm{D} . \mathrm{R})}= \pm 0.0645 \mathrm{~m}$.

Figure 5 displays the cumulative percentage frequencies of the deseasonated, depressured and detided residuals (points), together with that of the normal distribution (solid line). It is seen that the cumulative frequencies of the residuals that are larger than $| \pm 0.1|$, i.e. (D.R) $>1.5 \mathrm{~s}$ (D.R), deviate from those of the normal distribution. We assume that these residuals are most probably connected to some tectonic activity. The Figs. 6a, b and c are in favor of this assumption. These figures display the deseasonated, depressured and detided residuals (D.R), together with the shocks that have occurred in the respective time interval within the test area and are to be calculated together with Fig. 2, which displays the magnitude, the epicentral distances from Katerini as well as the time of the occurrences of the shocks. In these figures one has to reckon the values of the residuals in meters at the left scale and the magnitude of the shocks at the right scale. From these figures one realize that all of the shocks with magnitude higher than 2.5 and epicentral distance less than $40 \mathrm{~km}$ follow, as a single shock or as a member of a seismic series, residuals greater than \pm 0.1 with a phase lag of 7 to 0 days. It is to be noted that the shocks with magnitudes 2.4 to 3.1, which have occurred between the Julian dates 2451266 and 2451300 , do not correspond to any residual of large value. All these shocks, except the three shocks occurred around the Julian date of 2451280 with magnitude 2.4-2.6 which have an epicentral distance of $29.2 \mathrm{~km}$, and epicentral distances greater than $40 \mathrm{~km}$. This fact may reflect a distance magnitude effect on the seismic sensitivity of the well, but certainly many more observations are needed in order to conclude this definitely.

\section{Conclusion}

From the above results it is concluded that underground wa- ter level variations were clearly observed as precursory phenomena connected to the local microseismic activity in the area of Pieria. More observational material is needed in order to document a possible relation between the water level variations and the magnitude, epicentral distance and focal depth. In view of these results, we conclude that monitoring the underground water level and temperature for detecting earthquake precursory phenomena may be proved to be a useful method in the framework of an interdisciplinary research for earthquake prediction.

\section{References}

Arabelos, D.: Comparison of tidal parameters over a large area with respect to latitude, EGS XXVI General Assembly, Nice, 25-30 March, 2001.

Asteriadis, G. and Contadakis, M. E.: Variation on the Shallow Underground Water Level and Temperature Related to the Seismic Activity, Proceedings of the XXIII General Assembly of the European Seismological Commission, Prague 7-12 September 1992, Vol. II, 333-337, 1993.

Asteriadis, G. and Livieratos, E.: Pre-Seismic Responses of the Underground Water Level and Temperature concerning a 4.8 Magnitude Earthquake in Greece on 20 October 1988, Tectonophysics, 170, 165-169, 1989.

Contadakis, M. E. and Asteriadis, G.: Hydrologic changes as possible earthquake precursors in Greece, Natural Hazard, 23, 29-47, 2001.

Kilias, A., Frisch, W., Ratschbacher, L., and Sfeikos, A.: Structural evolution and metamorphism of bleuschist, Ampelakia nappe, eastern Thessaly, Greece, Bulletin of the Geological Society of Greece (in Greek, extending Abstract in English), Vol. XXV/1, 81-99, 1991.

Oki, Y. and Hiraga, S.: Groundwater monitoring for earthquake by an amateur network in Japan, Pageoph, 126, 2/4, 211-240, 1988.

Papazachos, B. C. and Papazachou, C.: The Earthquakes of Greece, Ziti Press, Thessaloniki, 1997.

Rikitake, T.: Current Research in Earthquake Prediction, I. Reidel, Dordrecht, 1981.

Wakita, H.: Earthquake Prediction Techniques, 175, Univ. of Tokyo Press, 1982.

Yamaguchi, R.: Changes in water level at Funabara and Kakigi before the Izu-Hanto-Toho-Oki, Earthquake of 1980, Bull. Earthquake Res. Inst. Univ. Tokyo, 55, 4, 1065, 1980. 